\title{
PEMBINAAN PROGRAM SPARK DALAM KALANGAN KANAK- KANAK BERUMUR 11 TAHUN: KAJIAN RINTIS
}

\author{
Nurul Diyana Binti Sanuddin \& Ahmad Bin Hashim \\ Fakulti Sains Sukan dan Kejurulatihan, Universiti Pendidikan Sultan Idris, \\ Tanjong Malim, Perak, Malaysia \\ Email: diyanasanuddin@gmail.com
}

\begin{abstract}
Abstrak
Jurnal Sains Sukan dan Pendidikan Jasmani 7(1): Received: 20 January 2018, Accepted: 20 February 2018 - Pembangunan program SPARK (Sport Play Active and Recreation for Kids) adalah satu usaha untuk meningkatkan aktiviti kecergasan fizikal dalam kalangan kanak-kanak sekolah. Selain itu, pembentukkan program ini adalah merupakan aktiviti yang terancang dan sistematik yang akan membantu kanak-kanak melahirkan idea secara bebas terutamanya dalam pembelajaran Pendidikan Jasmani ataupun semasa aktiviti Kokurikulum. Dalam kajian ini, kesahan kandungan tentang program SPARK adalah berdasarkan model pembinaan modul Sidek \& Jamaludin (2005). Proses penyediaan kandungan program SPARK (Sports Play Active and Recreation for Kids) bermula dengan pembinaan matlamat dan diakhiri dengan penyatuan draf. Pada peringkat permulaan pembinaan kandungan program ini, penyelidik menentukan tujuan, keperluan dan objektif utama program ini dijalankan serta jenis aktiviti-aktiviti yang sesuai diaplikasikan bagi meningkatkan aktiviti kecergasan fizikal pelajar. Oleh yang demikian, pembangunan program SPARK ini melalui dua fasa iaitu pembinaan program dan kesahan kandungan. Oleh itu, hasil penilaian pakar terhadap kandungan program SPARK (Sport Play Active and Recreation for Kids) ini, mempunyai nilai kesahan kandungan yang tinggi iaitu .78. Oleh itu, nilai ini dapat menjelaskan bahawa kandungan program SPARK (Sport Play Active and Recreation for Kids), adalah sangat releven digunapakai dalam proses pembelajaran dan pengajaran bagi subjek Pendidikan Jasmani, aktiviti kokurikulum mahupun aktiviti satu murid satu sukan dan ianya sangat sesuai untuk digunakan dalam kajian ini. Kesimpulannya, program yang diaplikasikan ini diharap dapat memberi peluang kepada kanakkanak menjalani pembelajaran secara semula jadi melalui sosial kognitif teori yang menyumbang kepada proses pembelajaran dan pengajaran bagi subjek Pendidikan Jasmani dan kesihatan bagi melihat kesan terhadap penglibatan aktiviti fizikal kanak-kanak.
\end{abstract}

Kata kunci: Program SPARK (Sport Play Active and Recreation for Kids), Kesahan Pakar Bidang, Aktiviti Kecergasan Fizikal. 


\title{
DEVELOPMENT OF SPARK PROGRAM IN 11 YEARS OLD CHILDREN: A PILOT STUDY
}

\begin{abstract}
The development of SPARK (Sport Play Active and Recreation for Kids) program is an effort to improve physical fitness activities among school children. In addition, the development of this program is planned and systematic activity that will help children express ideas freely, especially in the Physical Education or during Co-curriculum activities. In this study, the validity of the SPARK program is based on the Sidek \& Jamaludin (2005) module. The SPARK (Sports Play Active and Recreation for Kids) content creation process begins with the goal and concludes with a draft union. In the initial stages of the content development, researchers determine the purpose and objective of this program. Besides that, Researchers determine the appropriate types of activities are applied to enhance the physical fitness activities for the students. Therefore, the development of the SPARK program is through two phases, namely program construction and validity of content. Therefore, the results of the expert assessment on SPARK (Sport Play Active and Recreation for Kids) program content have a high content legality value of .78. This value can be explained that the SPARK program (Sport Play Active and Recreation for Kids) is highly relevant to the learning and teaching process for Physical Education subjects, co-curricular activities and it is ideal use in this research. In conclusion, the program is expected to provide opportunities for children to undergo natural learning through cognitive social theories that contribute to the learning and teaching process for Physical and Health Education subjects to see the impact on the involvement of children's physical activity.
\end{abstract}

Keywords: SPARK Program (Sport Play Active and Recreation for Kids), Expert Validity, Physical Fitness Activity 


\section{PENGENALAN}

Penglibatan dalam melakukan aktiviti fizikal yang kerap semasa zaman kanak-kanak dan remaja dikaitkan dengan peningkatan dalam pelbagai pembolehubah fisiologi dan psikologi. Sekolah merupakan satu institusi yang utama dan bertanggungjawab bagi menggalakkan aktiviti fizikal dalam dalam kalangan kanak-kanak sehingga remaja, 97\% daripada pelajar sekolah rendah mengambil subjek pendidikan jasmani (Hastie, 2017). Walau bagaimanapun, terdapat beberapa bukti menyatakan bahawa subjek pendidikan jasmani tidak memberikan kesan yang positif kepada peningkatan aktiviti kecergasan fizikal dalam kalangan kanak-kanak sekolah rendah (Marques, Gómez, Martins, Catunda, \& Sarmento, 2017).

Kajian sebelum ini, menyatakan bahawa hanya 3 minit pertama para pelajar terlibat secara aktif dalam aktiviti fizikal bagi subjek pendidikan jasmani iaitu kurang $10 \%$ tenaga yang digunakan untuk melakukan aktiviti fizikal di dalam kelas tersebut. Justeru, satu program yang sistematik dan efektif perlu dibina dalam subjek pendidikan jasmani yang bersesuaian dengan umur kanak-kanak sekolah rendah bagi menghasilkan kesan yang positif terhadap penigkatan kecergasan fizikal dan kesihatan (Fu, Gao, Hannon, Burns, \& Brusseau Jr, 2016).

Program SPARK merupakan salah satu program yang menunjukan peningkatan yang positif dalam melakukan aktiviti kecergasan fizikal di sekolah. Program SPARK terdiri daripada dua ciri utama iaitu aktiviti fizikal yang berkaitan kecergasan dan aktiviti kecergasan kemahiran yang memerlukan semangat, kerjasama dan keseronokan dalam menjalankan program ini (Herrick, Thompson, Kinder, \& Madsen, 2012). Program SPARK bermula sebagai satu program Pendidikan Jasmani yang berasakan penyelidikan bagi sekolah rendah tetapi kini program SPARK juga telah dijadikan satu progam Pendidikan Jasmani bagi sekolah menengah.

Program SPARK ini telah dibina oleh Sallis dan McKenzie pada tahun 1991, ia dibangunkan dari sudut pandangan kesihatan awam sebagai tindak balas kepada keperluan masyarakat untuk meningkatkan aktiviti fizikal dan kecergasan fizikal (Sallis, McKenzie, Alcaraz, Kolody, Faucette, \& Hovell, 1997). Program SPARK bukan sahaja diguna pakai semasa subjek Pendidikan Jasmani tetapi ia juga boleh digunakan selepas waktu persekolahan bagi menggalakkan generalisasi aktiviti fizikal dan kecergasan fizikal dalam kalangan pelajar (Kahan, \& McKenzie, 2017).

\section{Pernyataan Masalah}

Pengetahuan dan pembelajaran yang diperolehi semasa di dalam kelas Pendidikan Jasmani perlu disediakan dengan lebih sistematik dan effektif kerana ia dapat menarik minat kanakkanak untuk melakukan aktiviti fizikal seterusnya meningkatkan penglibatan dalam aktiviti kecergasan fizikal dan mengalakkan minat dalam gaya hidup sihat (Doozan, \& Bae, 2016). Sehubungan dengan itu, kajian yang berkaitan dengan pembelajaran dan program yang sistematik bagi subjek pendidikan jasmani amat kurang dijalankan (Chin, \& Ludwig, 2013). Oleh yang demikian, ia menunjukkan bahawa satu langkah yang proaktif perlu diambil kira bagi menarik minat kanak-kanak untuk terlibat secara aktif terhadap aktiviti fizikal. 


\section{Objektif Kajian}

Kajian ini bertujuan untuk membangunkan program SPARK (Sport Play Active and Recreation for Kids) untuk meningkatkan aktiviti kecergasan fizikal dalam kalangan kanak-kanak sekolah.

\section{METODOLOGI KAJIAN}

Kesahan merupakan satu perkara yang asas dalam kajian kuantitatif. Menurut Azizi dan rakanrakan (2007), kesahan merupakan salah satu konsep yang penting bagi menentukan konteks pengukuran konstruk ataupun gagasan seperti sikap, motivasi, persepsi, kecergasan dan pencapaian. Dalam membuat kesahan kandungan tentang program SPARK adalah berdasarkan model pembinaan modul Sidek dan Jamaludin (2005). Rajah 1 dibawah merujuk kepada proses pembinaan modul kandungan program SPARK (Sport Play Active and Recreation for Kids).

Proses penyediaan kandungan program SPARK (Sports Play Active and Recreation for Kids) bermula dengan pembinaan matlamat dan diakhiri dengan penyatuan draf. Pada peringkat permulaan pembinaan kandungan program ini, penyelidik menentukan tujuan, keperluan dan objektif utama program ini dijalankan serta jenis aktiviti-aktiviti yang sesuai diaplikasikan bagi meningkatkan aktiviti kecergasan fizikal pelajar. Pembinaan keseluruhan kandungan program ini, adalah merujuk kepada keperluan objektif pembelajaran dan pengajaran bagi subjek Pendidikan Jasmani dan Kesihatan berdasarkan tiga domain yang penting dalam program ini iaitu kecergasan, kemahiran dan keseronokan.

Sebelum reka bentuk kandungan ini disediakan, penyelidik telah mengenalpasti beberapa jenis teori yang terlibat dalam pembinaan kandungan program iaitu teori sosial ekologi model, dan sosial kognitif teori. Teori tersebut telah diaplikasikan dalam kandungan program ini bagi menghasilkan proses pembelajaran dan pengajaran yang berkesan. Seterusnya, para pelajar perlu memahami dan mempelajari setiap aktiviti yang dijalankan bagi meningkatkan tahap aktiviti kecergasan fizikal dan mengamalkan gaya hidup melalui pengetahuan dan kemahiran yang diperolehi sebelum ini.

Dalam pemilihan aktiviti bagi program ini, penyelidik telah memilih lapan (8) jenis aktiviti yang berdasarkan aktiviti kecergasan fizikal dan aktiviti kecergasan kemahiran. Pemilihan aktiviti dan strategi yang digunakan dalam program ini adalah berdasarkan domain yang telah ditetapkan oleh penyelidik bagi mendapatkan kesan yang positif dalam proses pembelajaran. Bagi mendapatkan keberkesanan program ini, peringkat seterusnya adalah penelitian kandungan program samaada program tersebut boleh digunakan oleh penyelidik dalam kajian ini. Kemudian, proses percubaan dan penambahbaikan program dijalankan. Jika kandungan program ini didapati tidak mencapai objektif yang telah ditetapkan oleh penyelidik, proses sebelum ini perlu dilakukan sekali lagi.

Bagi mendapatkan keputusan yang terbaik bagi mengenalpasti kandungan program yang boleh digunapakai dalam program ini, penyelidik telah merujuk kepada tiga orang pakar bidang bagi tujuan menganalisis dan membincangkan identifikasi keperluan proses pembelajaran dan pengajaran bagi para pelajar bagi subjek Pendidikan Jasmani dan Kesihatan. Kandungan dan jenis aktiviti di dalam program SPARK (Sport Play Active and Recreation for Kids) yang dibina oleh penyelidik telah disemak, diteliti sekali lagi dan dibetulkan berdasarkan 
maklumbalas dan nasihat pakar-pakar yang telah dipilih. Kandungan dan aktiviti program SPARK (Sport Play Active and Recreation for Kids) yang digunakan oleh penyelidik bagi menentukan pencapaian kesahan kandungan adalah dengan menggunakan instrumen kaji selidik yang berbentuk skala likert (Lampiran D) yang mempunyai 5 skala iaitu 5 (Sangat setuju), 4 (Setuju), 3 (Kurang Setuju), 2 (Tidak Setuju) dan 1 (Sangat tidak setuju).

Penilaian pakar yang digunakan adalah berdasarkan oleh formula yang telah dicadangkan oleh Sidek dan Jamaludin pada tahun 2005 seperti di bawah:

Jumlah Skor Pakar (X)

$\mathrm{X} 100 \%=$ Pencapaian Kesahan Kandungan Pakar

Skor Maksimum (45)

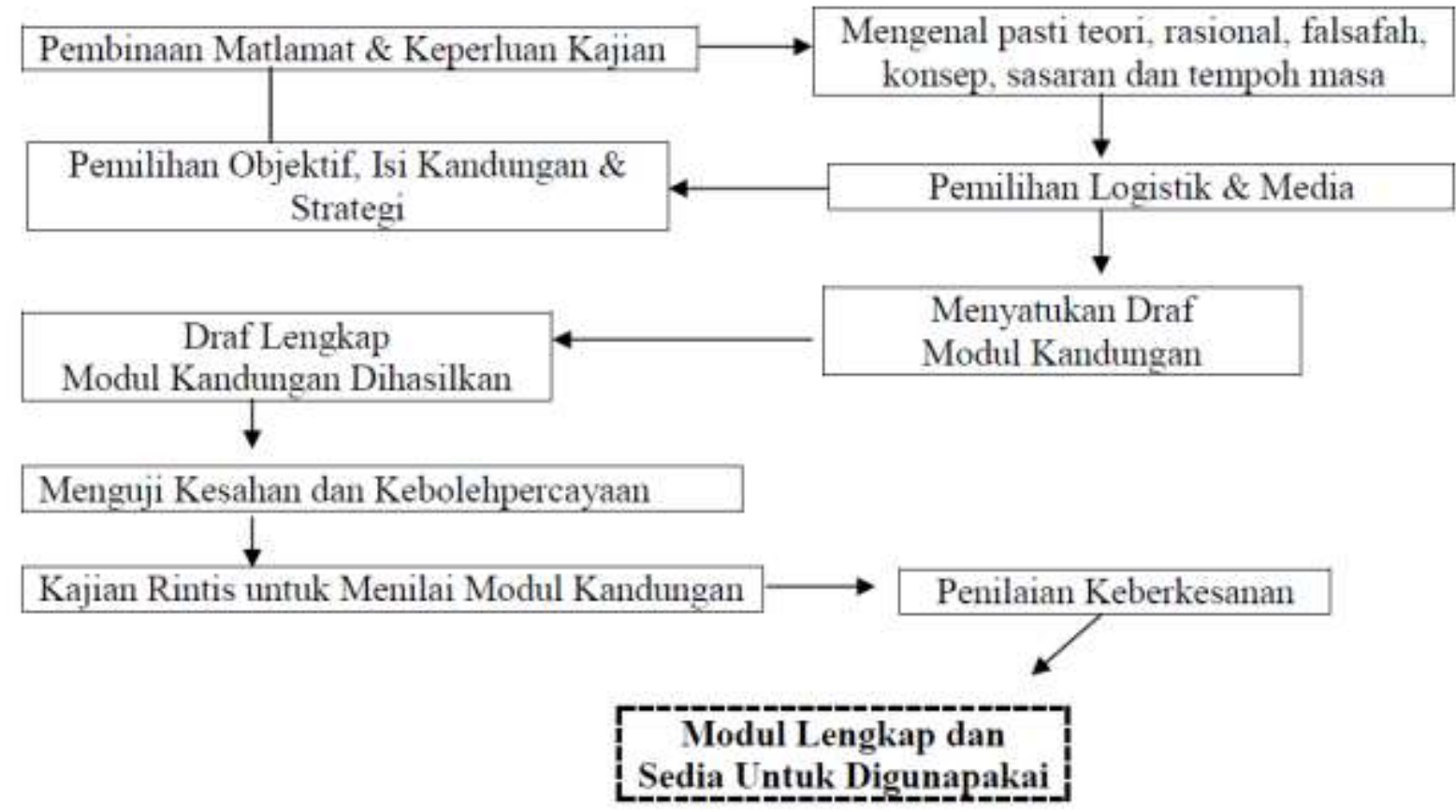

(Sumber: Sidek Mohd Noah \& Jamaludin Ahmad, 2005)

Rajah 1: Proses Pembinaan Modul Kandungan Program SPARK

\section{DAPATAN KAJIAN}

Jadual 1 di bawah menunjukkan nilai kesahan kandungan Program SPARK (Sport Play Active and Recreation for Kids) berdasarkan hasil penilaian oleh tiga orang pakar yang telah dipilih oleh penyelidik. 
Jadual 1 Kesahan kandungan Program SPARK (Pakar)

\begin{tabular}{lccc}
\hline Skor/ Pakar & Pakar 1 & Pakar 2 & Pakar 3 \\
\hline Item 1 & 5 & 5 & 4 \\
Item 2 & 4 & 4 & 4 \\
Item 3 & 5 & 4 & 4 \\
Item 4 & 4 & 4 & 4 \\
Item 5 & 4 & 4 & 4 \\
Item 6 & 5 & 5 & 4 \\
Item 7 & 4 & 4 & 5 \\
Item 8 & 4 & 4 & 4 \\
Item 9 & 5 & 4 & 4 \\
\hline Nilai $r$ & 0.75 & 0.79 & 0.81 \\
\hline
\end{tabular}

Nilai Keseluruhan $r=.78$

Menurut Tuckman (1978), nilai .60 dianggap telah dianggap telah menguasai atau mencapai tahap pencapaian yang tinggi. Oleh itu, hasil penilaian pakar terhadap kandungan program SPARK (Sport Play Active and Recreation for Kids) ini, mempunyai nilai kesahan kandungan yang tinggi iaitu .78. Oleh itu, nilai ini dapat menjelaskan bahawa kandungan program SPARK (Sport Play Active and Recreation for Kids), adalah sangat releven digunapakai dalam proses pembelajaran dan pengajaran bagi subjek Pendidikan Jasmani dan Kesihatan dan ianya sangat sesuai untuk digunakan dalam kajian ini.

\section{KESIMPULAN}

Kesimpulannya, program yang diaplikasikan ini diharap dapat memberi peluang kepada kanakkanak menjalani pembelajaran secara semula jadi melalui proses penerokaan, penemuan konsep baru, pengayaan dan pembinaan pengalaman. Selain itu juga, penerapan sosial kognitif teori dalam proses pembelajaran dan pengajaran bagi subjek Pendidikan Jasmani dan kesihatan diaplikasikan dalam program SPARK (Sports Play Active and Recreation for kids) dapat memberi kesan terhadap minat kanak- kanak dalam penglibatan aktiviti fizikal. Manakala Fisher (2011), menyatakan bahawa hubungan sosial yang kuat antara kanak-kanak akan berlaku apabila pengalaman pembelajaran yang menyeronokkan diberikan semasa proses pembelajaran itu sendiri kerana ianya dapat mengelakkan rasa bosan kanak-kanak terhadap mata pelajaran yang dipelajari, malah program ini dapat menimbulkan minat kanak-kanak terhadap pembelajaran yang dijalankan.

\section{RUJUKAN}

Azizi, Shahrin, Jamaludin, Yusof, \& Abdul Rahim. (2007). Menguasai penyelidikan dalam pendidikan: Teori, analisa, interpretasi data. Skudai, Johor: PTS.

Chin, J. J., \& Ludwig, D. (2013). Increasing children's physical activity during school recess periods. Revista Panamericana de Salud Pública, 34(5), 367-374. 
Doozan, A., \& Bae, M. (2016). Teaching physical literacy to promote healthy lives: TGfU and related approaches. The Physical Educator, 73, 471-487.

Fisher, A. (2011). Critical thinking: An introduction. Cambridge University Press.

Fu, Y., Gao, Z., Hannon, J. C., Burns, R. D., \& Brusseau Jr, T. A. (2016). Effect of the SPARK program on physical activity, cardiorespiratory endurance, and motivation in middle-school students. Journal of Physical Activity \& Health, 13(5).

Hastie, P. A. (2017). Revisiting the National Physical Education Content Standards: what do we really know about our achievement of the physically educated/literate person?. Journal of Teaching in Physical Education, 36(1), 3-19.

Herrick, H., Thompson, H., Kinder, J., \& Madsen, K. A. (2012). Use of SPARK to promote after-school physical activity. Journal of School Health, 82(10), 457-461.

Kahan, D., \& McKenzie, T. L. (2017). School and neighborhood predictors of physical fitness in elementary school students. Journal of School Health, 87(6), 448-456.

Marques, A., Gómez, F., Martins, J., Catunda, R., \& Sarmento, H. (2017). Association between physical education, school-based physical activity, and academic performance: a systematic review (Asociación entre la educación física, la actividad física en la escuela, y el rendimiento académico: una revisión sistemática). Retos, 31, 316-320.

Sallis, J. F., McKenzie, T. L., Alcaraz, J. E., Kolody, B., Faucette, N., \& Hovell, M. F. (1997). The effects of a 2-year physical education program (SPARK) on physical activity and fitness in elementary school students. Sports, Play and Active Recreation for Kids. American Journal of Public Health, 87(8), 1328-1334.

Sidek, M. N., \& Jamaludin, A. (2005). Pembinaan modul: Bagaimana membina modul latihan dan modul akademik. Serdang: Penerbit Universiti Putra Malaysia.

$\risingdotseq$ Nurul Diyana Binti Sanuddin

Fakulti Sains Sukan dan Kejurulatihan,

Universiti Pendidikan Sultan Idris,

35900 Tg Malim, Perak,

Malaysia 